\title{
An ICT solution for issues in communicable disease surveillance in Sri Lanka
}

\author{
Dr. W.M.A.S.B.Wickramasinghe \\ Dr. R.G.Premaratne \\ Dr. S.M.K.D. Arunatileka \\ University of Colombo, School of Computing, Sri Lanka. \\ Contact e-mail address: asangawick@gmail.com \\ eHealth Sri Lanka 2010,1(suppl.1):S3 \\ DOI: http://dx.doi.org/10.4038/sljbmi.v1i0.3535
}

Only the Abstract is available

\begin{abstract}
Early recognition of impending outbreaks followed by rapid response is the mainstay of controlling a communicable disease. Acquiring the ability for collection of complete data island wide in a timely manner and analysis of such data, timely dissemination of analysed data as well as guidelines on appropriate interventions will no doubt strengthen the Epidemiology Unit's (EU's) capacity to implement disease prevention and control activities more efficiently and effectively. Insight to the current communicable disease surveillance process reviled five issues which lead to delayed response to epidemics, which are 1) delays in data collection, 2) delays and limitations in data analysis, 3) delays in decision making, 4) delays in proactive measures and 5) delays in information dissemination. The concept of Nivārana came to life in order to strengthen the communicable disease surveillance by addressing the identified issues using Information and Communication Technology (ICT). Nivārana is a communicable disease surveillance and analysis system, focused on swift data collection, efficient data processing and rapid information dissemination in order to control and prevent communicable diseases by implementing rapid response to epidemics. Swift information dissemination is identified as the key to implement rapid response. People, process and technology were identified as the main aspects in the design, development and implantation. User understanding acquired by the pre-development survey and the established design consideration provided the ground for the design. System is developed as a web based system having data collection, data analysis, reporting and information dissemination as the core modules. Thorough analysis highlighted Java Technologies as the most appropriate for Nivārana implantation. The developed system is to be piloted in the Western Province in Sri Lanka shortly. Nivārana is conceptualised on the basis of "prevention is better than cure" and is used to translate information to swift public health action to minimise the burden of communicable diseases in Sri Lanka thereby preventing ill health and suffering in the community and conserving much needed resources.
\end{abstract}

Keywords - impending outbreaks, dissemination, Nivārana implantation 
eHealth Sri Lanka 2010,1(suppl.1):S3 